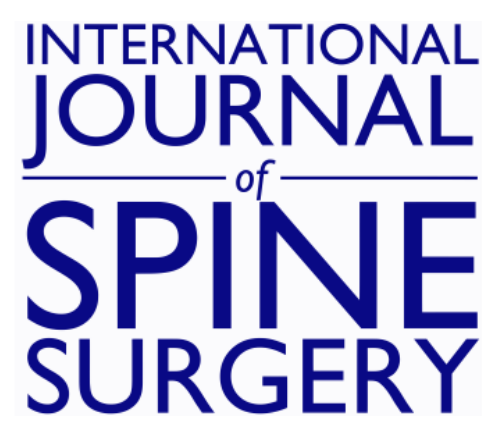

\title{
Women Do Not Have Poorer Outcomes After Minimally Invasive Lumbar Fusion Surgery: A Five-Year Follow-Up Study
}

WINSTON SHANG RONG LIM, MING HAN LINCOLN LIOW, GRAHAM S. GOH, WILLIAM YEO, ZHIXING MARCUS LING, WAI-MUN YUE, CHANG MING GUO and SEANG BENG TAN

Int J Spine Surg 2020, 14 (5) 756-761

doi: https://doi.org/10.14444/7108

http://ijssurgery.com/content/14/5/756

This information is current as of April 26, 2023.

Email Alerts Receive free email-alerts when new articles cite this article. Sign up at:

http://ijssurgery.com/alerts

The International Journal of Spine Surgery

2397 Waterbury Circle, Suite 1,

Aurora, IL 60504, Phone: +1-630-375-1432 


\title{
Women Do Not Have Poorer Outcomes After Minimally Invasive Lumbar Fusion Surgery: A Five-Year Follow-Up Study
}

\author{
WINSTON SHANG RONG LIM, MBBS, MRCS (Edin), ${ }^{1}$ MING HAN LINCOLN LIOW, MBBS, FRCS \\ (Edin)(Ortho), ${ }^{1}$ GRAHAM S. GOH, MBBS, MRCS (Edin), ${ }^{1}$ WILLIAM YEO, BAppSc, MPhty ${ }^{1}$, ZHIXING \\ MARCUS LING MBBS, MRCS (Glas), FRCS (Edin), ${ }^{1}$ WAI-MUN YUE, MBBS, FRCS (Edin), ${ }^{2}$ CHANG MING \\ GUO, MBBS, FRCS (Edin), ${ }^{1}$ SEANG BENG TAN, MBBS, FRCS (Edin) ${ }^{3}$ \\ ${ }^{I}$ Department of Orthopedic Surgery, Singapore General Hospital, Singapore, ${ }^{2}$ The Orthopaedic Centre, Mount Elizabeth Medical Centre, Singapore, ${ }^{3}$ Orthopaedic \\ and Spine Clinic, Mount Elizabeth Novena Medical Centre, Singapore
}

\begin{abstract}
Background: Women undergoing lumbar spine surgery report greater preoperative pain and disability and have less improvement after surgery. There is a paucity of literature on sex-related differences after minimally invasive surgery transforaminal lumbar interbody fusion (MIS TLIF) surgery. We aim to determine whether sex influences outcome after MIS TLIF at 5-year midterm follow-up.

Methods: Prospectively collected registry data for 907 patients who underwent MIS TLIF at a single institution from 2004 to 2013 were reviewed. Of these, 296 patients (94 males and 202 females) were reviewed at 5-year follow-up. All patients were assessed preoperatively and postoperatively at 2 and 5 years. Data recorded included patient demographics, Oswestry Disability Index (ODI), Short-Form 36 Physical and Mental component scores (SF-36 PCS and MCS), and the North American Spine Society lumbar spine outcome assessment instrument.

Results: Females who underwent MIS TLIF were generally younger (females, 52.2 years; males, 56.1 years; $P=$ .04 ). Females had significantly poorer preoperative ODI (females, 49.5; males, 41.5; $P<.001$ ) and SF-36 PCS (females, 31.9; males, 35.6; $P<.01$ ) and MCS (females, 44.9; males, 49.2; $P<.01$ ) scores. At 2-year and 5-year follow-up, there were no significant differences in ODI, SF-36, and pain scores between sexes. Both groups reported similar proportions that returned to work and returned to function. There were no differences in proportion of patients who were satisfied or had their expectations fulfilled.

Conclusions: Women who undergo MIS TLIF have poorer preoperative function and quality of life than men. However, women demonstrated greater improvement after surgery, attaining similar clinical outcomes at 5-year followup.

Level of Evidence: 3.
\end{abstract}

Minimally Invasive Surgery

Keywords: minimally invasive surgery, gender, transforaminal lumbar interbody fusion, spinal stenosis, patient reported outcome measure

\section{INTRODUCTION}

Lumbar fusion surgery is a common surgical procedure used to address patients with symptomatic spinal stenosis who fail conservative treatment. Traditionally, transforaminal lumbar interbody fusion (TLIF) procedures are performed openly, which requires extensive muscle retraction and soft tissue dissection. Advances in minimally invasive (MIS) techniques offer less blood loss, earlier ambulation, shorter hospitalization, and lower costs compared with open surgery. ${ }^{1-3}$
There appears to be a paucity of literature in sexrelated differences in lumbar spine surgery. According to the Swedish Spine Registry, women who undergo surgery for lumbar disc herniation have more preoperative back pain, more disability, and poorer quality of life. Even postoperatively, women report higher levels of back and leg pain and less improvement in disability. ${ }^{4}$ A similar trend was even observed in young children, where girls reported more pronounced back pain 1 year after surgery. ${ }^{5}$

To our knowledge, our paper is the first to examine sex-related differences in outcome after MIS TLIF surgery. We hypothesize that women 
may not improve as much as men do after surgery, given that women have greater pain sensitivity, enhanced pain facilitation, and reduced pain inhibition. ${ }^{6}$ The aim of our study is to determine if sex influences functional, patient-reported outcome measures, health-related quality of life, satisfaction, and fulfillment of outcomes after MIS TLIF at 5year follow-up.

\section{PATIENTS AND METHODS}

Appropriate ethics approval was obtained from our institution's review board before this study was conducted. We reviewed prospectively collected registry data for 907 patients who underwent MIS TLIF at our hospital between 2004 and 2013. Our inclusion criteria were (1) symptomatic spinal stenosis with failure of conservative management; (2) a history of primary single-level MIS-TLIF; and (3) complete preoperative, 2-year and 5-year followup data. The indications for surgery included: (1) grade 1 or 2 degenerative spondylolisthesis and (2) nerve compression symptoms, such as radicular pain, paraesthesia, or neurogenic claudication. All patients failed a trial of conservative management of at least 6 weeks before surgery. We excluded patients with (1) previous back surgery with spinal instrumentation, (2) thoracolumbar spinal instrumentation, (3) spinal infection, (4) tumor-related spinal pathology, and (5) acute spinal trauma.

All patients were evaluated preoperatively with static (erect anteroposterior and lateral) and dynamic (flexion and extension) plain lumbar spine radiographs and magnetic resonance imaging of the lumbar spine. All patients were assessed preoperatively and postoperatively at 2 and 5 years by independent assessors, with numerical pain rating scale (NPRS back and leg pain), Oswestry Disability Index (ODI), Short-form 36 Physical and Mental component scores (SF-36 PCS and MCS), and North American Spine Society (NASS) score for neurogenic symptoms recorded. Patients' comorbidities, length of operation and hospitalization, duration to return to work and return to function, as well as satisfaction of surgery and expectation fulfillment, was also recorded.

\section{Surgical Technique}

All single-level MIS-TLIF surgeries were performed by the senior authors of this study. The TLIF surgical approach was decided based on the symptomatic side. If both sides were symptomatic, the incision would be on the side of more severe pathology. A mobile $\mathrm{C}$ arm image intensifier was used to confirm the desired operative level. A parasagittal incision was made lateral to the midline, followed by the establishment of an endoscopic port with sequential soft tissue dilators inserted down to the facet complex. Facetectomy was performed using a high-speed burr to expose the posterior lateral aspect of the disc. Discectomy was performed, and end plates were prepared. Disc space distraction was also performed with intradiscal spreaders before the placement of bone graft anterior and contralateral to the annulotomy, followed by an interbody cage. Fluoroscopy was used to ensure the satisfactory placement of the interbody cage. Decompression was then performed by removing the rest of the ipsilateral facet and lamina and resecting the lateral margin of the ligamentum flavum to expose the ipsilateral exiting and traversing roots. The adequacy of decompression was assessed by using a ball tip probe to palpate the nerve root as it entered the foramen. After decompression, the percutaneous pedicle screw-rod construct was placed through the same incision and another similar construct through a contralateral incision. Compression was applied before final tightening of the construct in order to attempt to restore lordosis. Hemostasis and wound irrigation were performed before closure in layers.

A standardized postoperative rehabilitation program was conducted for all patients. Barring any medical contraindication, patients were typically given oral paracetamol, a selective cyclooxygenase-2 (COX-2) inhibitor, such as etoricoxib, and intravenous patient-controlled morphine. Patients were encouraged to ambulate as soon as tolerated, usually from the day after surgery. The patients were discharged once they were able to ambulate safely with a walking stick.

\section{Statistical Methods}

A power analysis was conducted with type I error set at 0.05 and type II error at 0.20 (power $80 \%$ ). A minimum sample size of 40 patients in each group was required to detect the minimum clinically important difference in ODI of $12.8,^{7}$ from a baseline score of 41 and with a standard deviation of 20 points.

Statistical analysis was performed using SPSS version 20.0. Student $t$ test and $\chi^{2}$ test was used to 
Table 1. Patient demographics $(n=296)$.

\begin{tabular}{|c|c|c|c|}
\hline Patient Demographics & $\begin{array}{c}\text { Male } \\
(n=94)\end{array}$ & $\begin{array}{c}\text { Female } \\
(\mathrm{n}=\mathbf{2 0 2})\end{array}$ & $\begin{array}{c}P \\
\text { Value }\end{array}$ \\
\hline Age, $y$ & $56.1 \pm 11.6$ & $52.2 \pm 3.2$ & .04 \\
\hline Body mass index, $\mathrm{kg} / \mathrm{m}^{2}$ & $25.0 \pm 3.5$ & $29.9 \pm 5.3$ & .51 \\
\hline Length of procedure, min & $170.4 \pm 47.3$ & $170.0 \pm 53.5$ & .95 \\
\hline Length of stay, days & $3.4 \pm 3.5$ & $3.6 \pm 1.8$ & .68 \\
\hline \multicolumn{4}{|l|}{ Comorbidities, $\%$} \\
\hline Diabetes & 11.7 & 11.4 & .91 \\
\hline Ischemic heart disease & 6.4 & 5.4 & .96 \\
\hline Osteoarthritis & 7.4 & 17.3 & .04 \\
\hline Asthma & 3.2 & 3.0 & .80 \\
\hline Depression & 3.1 & 2.9 & .79 \\
\hline Hypertension & 35.1 & 42.1 & .31 \\
\hline Hypercholesterolemia & 31.9 & 35.1 & .68 \\
\hline Renal disease & 1.0 & 0.99 & .57 \\
\hline \multicolumn{4}{|l|}{ Preoperative clinical outcomes } \\
\hline Oswestry Disability Index ${ }^{a}$ & $41.5 \pm 18.0$ & $49.5 \pm 17.3$ & $<.001$ \\
\hline NASS neurogenic symptoms ${ }^{a}$ & $46.8 \pm 24.3$ & $52.2 \pm 23.0$ & .06 \\
\hline SF-36 Physical Component score & $35.6 \pm 10.6$ & $31.9 \pm 10.3$ & $<.01$ \\
\hline SF-36 Mental Component score & $49.2 \pm 11.7$ & $44.9 \pm 12.3$ & $<.01$ \\
\hline $\begin{array}{l}\text { Numerical pain rating scale } \\
\text { (back pain) }\end{array}$ & $5.7 \pm 2.8$ & $6.1 \pm 2.8$ & .20 \\
\hline $\begin{array}{l}\text { Numerical pain rating scale } \\
\text { (leg pain) }\end{array}$ & $7 \pm 6.2$ & $6.1 \pm 3.1$ & .21 \\
\hline
\end{tabular}

Abbreviation: NASS, North American Spine Society. Bold indicates statistically significant.

${ }^{\mathrm{a}}$ Lower is better.

compare parametric and proportion-based outcomes respectively between sexes. Multiple logistic regression was performed with sex as the dependent variable to identify associated independent variables. Results of $P<0.05$ were considered to be statistically significant.

\section{RESULTS}

A total of 296 patients (94 males and 202 females) had complete preoperative data and were reviewed at 2 and 5 years. The preoperative patient demographics are displayed in Table 1. Female patients were significantly younger than male patients at time of surgery (females, 52.2 years; males, 56.1 years; $P=.04$ ). Females also had a significantly higher prevalence of osteoarthritis (females, 17.3\%; males, $7.4 \% ; P=.04)$. There were no other significant differences in body mass index or operative time or length of hospitalization.

Female patients had a significantly higher preoperative ODI score compared with male patients (females, 49.5; males, 41.5; $P<.001$ ), indicating increased disability from back and leg pain. Females also experienced poorer preoperative quality of life, scoring lower in the SF-36 PCS and MCS (SF-36 PCS: females, 31.9; males, 35.6; $P<.01$; SF-36 MCS: females, 44.9; males, 49.2; $P<.01$ ).

Both sexes improved postoperatively, and this improvement was sustained even at 5 years (Table
Table 2. Comparison of clinical outcomes at different time intervals.

\begin{tabular}{|c|c|c|c|}
\hline Time Interval & $\begin{array}{c}\text { Male } \\
(\mathrm{n}=94)\end{array}$ & $\begin{array}{c}\text { Female } \\
(\mathrm{n}=\mathbf{2 0 2})\end{array}$ & $\begin{array}{c}P \\
\text { Value }\end{array}$ \\
\hline \multicolumn{4}{|l|}{ Comparison at $2 \mathrm{y}$} \\
\hline Oswestry Disability Index ${ }^{a}$ & $13.8 \pm 15.2$ & $15.3 \pm 15.7$ & 41 \\
\hline NASS neurogenic symptoms ${ }^{\mathrm{a}}$ & $10.6 \pm 16.3$ & $11.8 \pm 18.7$ & 61 \\
\hline SF-36 Physical Component score & $47.6 \pm 10.2$ & $47.6 \pm 10.9$ & .99 \\
\hline SF-36 Mental Component score & $54.1 \pm 10.5$ & $52.5 \pm 11.6$ & .25 \\
\hline $\begin{array}{l}\text { Numerical pain rating scale } \\
\text { (back pain) }\end{array}$ & $1.2 \pm 2.3$ & $1.5 \pm 2.4$ & .40 \\
\hline $\begin{array}{l}\text { Numerical pain rating scale } \\
\text { (leg pain) }\end{array}$ & $0.6 \pm 1.7$ & $1.0 \pm 2.0$ & .06 \\
\hline \multicolumn{4}{|l|}{ Comparison at $5 \mathrm{y}$} \\
\hline Oswestry Disability Index ${ }^{a}$ & $12.0 \pm 13.5$ & $12.9 \pm 15.0$ & .63 \\
\hline NASS neurogenic symptoms $\mathrm{s}^{\mathrm{a}}$ & $8.3 \pm 10.2$ & $10.2 \pm 20.4$ & .42 \\
\hline SF-36 Physical Component score & $46.5 \pm 10.0$ & $47.6 \pm 10.1$ & .37 \\
\hline SF-36 Mental Component score & $54.7 \pm 10.2$ & $52.3 \pm 12.0$ & .10 \\
\hline $\begin{array}{l}\text { Numerical pain rating scale } \\
\text { (back pain) }\end{array}$ & $0.8 \pm 2.1$ & $1.2 \pm 2.4$ & .08 \\
\hline $\begin{array}{l}\text { Numerical pain rating scale } \\
\text { (leg pain) }\end{array}$ & $0.5 \pm 1.9$ & $0.7 \pm 1.9$ & .48 \\
\hline
\end{tabular}

Abbreviation: NASS, North American Spine Society.

${ }^{\text {a }}$ Lower is better.

2). There were no significant differences between both sexes. At 2 years, most patients were able to return to work (females, $98.7 \%$; males, $96.6 \%$ ). The proportion of female patients who were able to return to work with no limitations increased from $60.3 \%$ at 2 years to $76.4 \%$ at 5 years (Table 3 ). A higher proportion of patients were also able to return to function after surgery at 5 years (females, $78.7 \%$; males, $73.4 \%$ ) compared with 2 years after surgery (females, 65.8\%; males, 62.8\%). 52.7\% of cases were performed via the left side, whereas $47.3 \%$ were from the right. There were no significant differences in SF-36 or back pain or leg pain at 5 years dependent on the side of the approach.

Most patients were satisfied with the outcome of surgery and had their expectations fulfilled (Table $3)$. A higher proportion of males were satisfied at 5 years $(89.4 \%)$ compared with 2 years $(81.9 \%)$ after surgery. There were no significant differences in

Table 3. Return to work and return to function at different time intervals.

\begin{tabular}{lccc}
\hline Time Interval & $\begin{array}{c}\text { Male } \\
(\mathbf{n = 9 4 )}\end{array}$ & $\begin{array}{c}\text { Female } \\
(\mathbf{n = 2 0 2})\end{array}$ & $\boldsymbol{P}$ Value \\
\hline Comparison at 2 y & & & .60 \\
Return to work, \% & & & \\
$\quad$ No & 3.4 & 1.4 & .70 \\
$\quad$ Yes, with limitations & 32.2 & 38.4 & .09 \\
$\quad$ Yes, with no limitations & 64.4 & 60.3 & \\
Return to function, \% & 62.8 & 65.8 & \\
Comparison at 5 y & & & \\
Return to work, \% & & & .39 \\
$\quad$ No & 5.2 & 0.0 & \\
$\quad$ Yes, with limitations & 29.3 & 23.6 & \\
$\quad$ Yes, with no limitations & 65.5 & 76.4 & \\
Return to function, \% & 73.4 & 78.7 & \\
\hline
\end{tabular}


Table 4. Satisfaction and fulfillment of expectations at different time intervals.

\begin{tabular}{|c|c|c|c|c|c|c|}
\hline & \multicolumn{3}{|c|}{$2 y$} & \multicolumn{3}{|c|}{$5 y$} \\
\hline & Male & Female & $P$ Value & Male & Female & $P$ Value \\
\hline Satisfied, \% & 81.9 & 87.6 & .26 & 89.4 & 88.6 & .99 \\
\hline Dissatisfied, $\%$ & 18.1 & 12.4 & & 10.6 & 11.4 & \\
\hline Expectations fulfilled, \% & 91.5 & 92.1 & .96 & 92.6 & 94.1 & .81 \\
\hline Expectations not fulfilled, $\%$ & 8.5 & 7.9 & & 7.4 & 5.9 & \\
\hline
\end{tabular}

satisfaction and expectation fulfilment between sexes at 2 and 5 years (Table 4 ).

A total of 9 female patients underwent revision surgery: 1 required pedicle screw removal for painful implants, 1 required revision because a screw had perforated the lateral pedicle wall, causing radicular pain, 1 patient had cage subsidence and screw cut-out, and 1 required screw removal and intertransverse fusion because scarring around the nerve root was causing recurrent radicular pain. Five required revision surgery for adjacent segment disease. A total of 3 male patients underwent revision surgery for adjacent segment disease. There were no significant differences in revision rate between both sexes $(P=.75)$. There were 4 cases of inadvertent durotomy in the female group and none in the male group. There was also 1 case in the female group of vertebral end plate perforation by the interbody cage, but it required no salvage procedures.

\section{DISCUSSION}

It is well established that there are differences in pain perception between men and women-women tend to experience greater clinical pain and suffer greater pain-related distress. ${ }^{8}$ Katz et al ${ }^{9}$ examined 154 patients who underwent laminectomy for spinal stenosis and found that women had poorer preoperative function compared with men. ${ }^{9}$ In our study, female patients also had poorer preoperative function, experienced greater disability, and reported poorer quality of life compared with males prior to surgery. This was despite reporting a similar severity of back pain (females, 6.1; males, 5.7) and leg pain (females, 6.1; males, 5.7) according to the NPRS, suggesting that pain alone does not fully account for preoperative function and quality of life in women with degenerative spine disease. A study by Kim et $\mathrm{al}^{10}$ suggested that pain catastrophizing could be a potential mediator of sex difference for disability. The study by Kim et $\mathrm{al}^{10}$ found that females with lumbar spinal stenosis had greater pain catastrophizing compared with males, and this caused a significant negative influence on disability. Our findings are similar to a recent similar study by Khechen et al, ${ }^{11}$ who examined short-term 6-month outcomes between male and female patients after MIS TLIF. In their retrospective single-surgeon review, they also found that female patients had greater preoperative pain and disability compared with men, but by 6 months postoperatively there was no significant difference between both sexes.

Some high-volume spine surgery centers have been performing MIS TLIF as a day procedure, ${ }^{12}$ with patients being discharged on the same day of the procedure. In our study, none of the cases were performed as a day procedure. Nonetheless, there were no significant differences in length of stay between both sexes (male, 3.4 days; females, 3.6 days; $P=.68$ ). Our institution's length of stay is similar to those of others reported in literature, as well as locally, which range from 2.3 to 10.6 days. ${ }^{13,14}$ Typically, we would at least observe our patients overnight to ensure adequate pain control, stable vital signs and neurologic examination, voiding, and ability to ambulate.

Even though female patients had greater disability preoperatively, they managed to achieve similar functional outcomes when compared to males at midterm follow-up of 5 years. The reduction in pain, and improvement in function and quality of life were durable and sustained in both sexes at 5 years. This finding is similar to those of a previous study by Rouben et al, ${ }^{15}$ whose study of 169 patients who underwent single- or 2-level MIS TLIF, found that the improvement in VAS and ODI was sustained for up to 49 months after surgery. Their study reported a $41 \%$ improvement in ODI at 49 months, from an ODI of 68 to 30 in single-level fusion cases and 73 to 27 in 2-level fusion cases.

Cost-effectiveness studies examining TLIF surgeries have shown that missed work after surgery results in increased costs and reduced productivity. ${ }^{16}$ Some patients may believe that undergoing surgery may cause them to lose their jobs, and choose to live with chronic pain. The ability for 
preoperative working patients to return to work after surgery is particularly important in workingage adults considering surgery. There is a relative paucity of literature on the ability to return to work after spine surgery. Of note, the ability to return to work is increasingly incorporated into clinical outcome studies. ${ }^{17,18}$

Several authors have found that MIS TLIF confers an advantage compared with open TLIF in relation to time to return to work. ${ }^{18}$ In a retrospective cohort comparison of 30 patients, Adogwa et $\mathrm{al}^{16}$ found that the median time to return to work was 8.5 weeks for patients who underwent MIS TLIF, and 17.1 weeks for patients who underwent open TLIF. This was not surprising, given that there is less soft tissue dissection, lower blood loss, and less postoperative pain in MIS techniques. ${ }^{1}$ This study is the first to investigate the effect of sex on a patient's ability to return to work at 5 years after MIS-TLIF. Our study found that $60.3 \%$ of females and $64.4 \%$ of males in our study were able to return to work without limitation at 2 years, with no difference between sexes. The proportion of females who were able to return to work without limitation increased to $76.4 \%$ at 5 years.

As countries look for various ways to improve health care and contain costs, the pay-for-performance model has been increasingly adopted. Quantifiable patient satisfaction is being used as a metric for measuring patient experience, and hospitals are in turn rewarded or penalized based on their patient satisfaction scores. ${ }^{19}$ Although controversy exists around whether increased patient satisfaction translates to improved clinical outcome, ${ }^{20}$ it remains a useful tool to gauge the success of surgery from a patient's point of view. In a study of 1645 patients undergoing elective spine surgery for degenerative conditions, Chotai et $\mathrm{al}^{21}$ found that surgical ineffectiveness was a strong predictor of dissatisfaction at 1 year, but sex itself was not a predictor of dissatisfaction. Our study revealed that there was no difference in the proportion of males and females who were satisfied at 5 years (males, 89.4\%; females, $88.6 \% ; P=.99)$. The link between satisfaction and expectation fulfillment remains unclear. Multiple studies have found that patients undergoing spine surgery optimistically expect to have great improvement in their state of health, function, and pain. ${ }^{22-24}$ Even though these expectations are not necessarily achieved after surgery, it did not appear to affect patient satisfaction. $^{22}$

Our study has several limitations. First, this was a retrospective review of a consecutive series of patients. The outcomes data used in this study were prospectively collected as part of the normal scope of practice, which likely minimizes any selection bias because the data were systematically and consecutively collected. Second, confounding variables may have contributed to the reported preoperative difference in functional outcomes between sexes because of differences in baseline comorbidities and characteristics. However, both sexes had similar comorbidity profiles, with the exception that females had an increased prevalence of osteoarthritis. Lastly, this study does not include radiographic data to assess fusion and sagittal balance. Several studies have not been able to show a direct correlation between radiographic fusion and patient-reported outcome measures. ${ }^{25,26}$ The strengths of this study include the relatively large number of patients operated on by fellowship-trained surgeons with 5-year follow-up, combined with data prospectively collected by independent assessors.

In conclusion, women who elect to undergo MIS TLIF have poorer preoperative function and quality of life scores compared with men. Despite that, women were able to attain similar and sustained clinical outcome compared with men up to 5 years postoperatively. This suggests that poorer preoperative function in females should not deter surgeons from recommending patients for MIS TLIF surgery when indicated.

\section{REFERENCES}

1. Seng C, Siddiqui MA, Wong KP, et al. Five-year outcomes of minimally invasive versus open transforaminal lumbar interbody fusion: a matched-pair comparison study. Spine. 2013;38(23):2049-2055.

2. Peng CW, Yue WM, Poh SY, Yeo W, Tan SB. Clinical and radiological outcomes of minimally invasive versus open transforaminal lumbar interbody fusion. Spine. 2009;34(13):13851389.

3. Singh K, Nandyala SV, Marquez-Lara A, et al. A perioperative cost analysis comparing single-level minimally invasive and open transforaminal lumbar interbody fusion. Spine J. 2014;14(8):1694-1701.

4. Stromqvist F, Ahmad M, Hildingsson C, Jonsson B, Stromqvist B. Gender differences in lumbar disc herniation surgery. Acta Orthop. 2008;79(5):643-649.

5. Stromqvist F, Stromqvist B, Jonsson B, Gerdhem P, Karlsson MK. Lumbar disc herniation surgery in children: outcome and gender differences. Eur Spine J. 2016;25(2):657663. 
6. Tschugg A, Loscher WN, Hartmann S, Neururer S, Wildauer M, Thome C. Gender influences radicular pain perception in patients with lumbar disc herniation. $J$ Women's Health (Larchmt). 2015;24(9):771-776.

7. Copay AG, Glassman SD, Subach BR, Berven S, Schuler TC, Carreon LY. Minimum clinically important difference in lumbar spine surgery patients: a choice of methods using the Oswestry Disability Index, Medical Outcomes Study questionnaire Short Form 36, and pain scales. Spine J. 2008;8(6):968974.

8. Paller CJ, Campbell CM, Edwards RR, Dobs AS. Sexbased differences in pain perception and treatment. Pain Med. 2009;10(2):289-299.

9. Katz JN, Wright EA, Guadagnoli E, Liang MH, Karlson EW, Cleary PD. Differences between men and women undergoing major orthopedic surgery for degenerative arthritis. Arthritis and Rheum. 1994;37(5):687-694.

10. Kim HJ, Cho CH, Kang KT, Chang BS, Lee CK, Yeom JS. The significance of pain catastrophizing in clinical manifestations of patients with lumbar spinal stenosis: mediation analysis with bootstrapping. Spine J. 2015;15(2):238-246.

11. Khechen B, Haws BE, Patel DV, Cardinal KL, Guntin JA, Singh K. Does gender influence postoperative outcomes in minimally invasive transforaminal lumbar interbody fusion? Clin Spine Surg. 2019;32(2):e107-e111.

12. Eckman WW, Hester L, McMillen M. Same-day discharge after minimally invasive transforaminal lumbar interbody fusion: a series of 808 cases. Clin Orthopaedics Relat Res. 2014;472(6):1806-1812.

13. Phan K, Rao PJ, Kam AC, Mobbs RJ. Minimally invasive versus open transforaminal lumbar interbody fusion for treatment of degenerative lumbar disease: systematic review and meta-analysis. Eur Spine J. 2015;24(5):1017-1030.

14. Hey HW, Hee HT. Open and minimally invasive transforaminal lumbar interbody fusion: comparison of intermediate results and complications. Asian Spine $J$. 2015;9(2):185-193.

15. Rouben D, Casnellie M, Ferguson M. Long-term durability of minimal invasive posterior transforaminal lumbar interbody fusion: a clinical and radiographic follow-up. J Spinal Disord Techniques. 2011;24(5):288-296.

16. Adogwa O, Parker SL, Bydon A, Cheng J, McGirt MJ. Comparative effectiveness of minimally invasive versus open transforaminal lumbar interbody fusion: 2-year assessment of narcotic use, return to work, disability, and quality of life. $J$ Spinal Disord Techniques. 2011;24(8):479-484.

17. Anderson JT, Haas AR, Percy R, Woods ST, Ahn UM, Ahn NU. Return to work after diskogenic fusion in workers' compensation subjects. Orthopedics. 2015;38(12):e1065-1072.

18. Parker SL, Lerner J, McGirt MJ. Effect of minimally invasive technique on return to work and narcotic use following transforaminal lumbar inter-body fusion: a review. Prof Case Manag. 2012;17(5):229-235.

19. Mehta SJ. Patient satisfaction reporting and its implications for patient care. AMA J Ethics. 2015;17(7):616621.

20. Fenton JJ, Jerant AF, Bertakis KD, Franks P. The cost of satisfaction: a national study of patient satisfaction, health care utilization, expenditures, and mortality. Arch Intern Med. 2012;172(5):405-411.

21. Chotai S, Sivaganesan A, Parker SL, McGirt MJ, Devin CJ. Patient-specific factors associated with dissatisfaction after elective surgery for degenerative spine diseases. Neurosurgery. 2015;77(2):157-163; discussion 163.

22. McGregor AH, Dore CJ, Morris TP. An exploration of patients' expectation of and satisfaction with surgical outcome. Eur Spine J. 2013;22(12):2836-2844.

23. Mannion AF, Junge A, Elfering A, Dvorak J, Porchet F, Grob D. Great expectations: really the novel predictor of outcome after spinal surgery? Spine. 2009;34(15):1590-1599.

24. Yee A, Adjei N, Do J, Ford M, Finkelstein J. Do patient expectations of spinal surgery relate to functional outcome? Clin Orthop Relat Res. 2008;466(5):1154-1161.

25. Liow MHL, Lee M, Goh GS, et al. Poorer fusion outcomes in diabetic cervical spondylotic myelopathy patients undergoing single-level anterior cervical discectomy and fusion does not compromise functional outcomes and quality of life. Spine. 2018;43(7):477-483.

26. Giorgi H, Prebet R, Delhaye M, et al. Minimally invasive posterior transforaminal lumbar interbody fusion: one-year postoperative morbidity, clinical and radiological results of a prospective multicenter study of 182 cases. Orthop Traumatol Surg Res. 2015;101(6 suppl):S241-S245.

Disclosures and COI: The authors declare no conflict of interest regarding the publication of this article.

Corresponding Author: Winston Shang Rong Lim, Department of Orthopaedic Surgery, Singapore General Hospital, 20 College Road, Academia, Level 4, Singapore 169865. Phone: (65) 62223322; Email: winston.lim@mohh.com.sg.

Published 11 November 2020

This manuscript is generously published free of charge by ISASS, the International Society for the Advancement of Spine Surgery. Copyright (c) 2020 ISASS. To see more or order reprints or permissions, see http://ijssurgery.com. 